\title{
CONGENITAL HEART BLOCK WITH ATRIAL AND VENTRICULAR SEPTAL DEFECT
}

\author{
By A. A. FITZGERALD PEEL \\ From the Cardiographic Department, Victoria Infirmary, Glasgow \\ Received September 21, 1942
}

The combination of atrial septal defect with congenital complete heart block is of sufficient rarity to justify publication of the following case.

Case report.-A woman, aged 46, unmarried.

As far as can be ascertained, no abnormality was noted during the first five years of life. When the patient was 5 , her mother died suddenly from heart disease, whereupon her grandfather had the patient medically examined; her heart was said to be weak and she was put to bed for a month. Shortly after this she had scarlet fever and then diphtheria, and was very ill with the latter. At school she was short of breath and was unable to run ; she remembers that her face was highly coloured, and that she was repeatedly off school for a week at a time. After leaving school she did office work for seven years ; she occasionally had to take an afternoon's rest, but was seldom off for longer. For the next few years she was at home, and enjoyed fairly good health, but suffered from "slight attacks of breathlessness and dizziness " from time to time. In 1930 she underwent an operation for strangulated hernia.

In 1934 she was admitted to hospital. She had "felt seedy" on the previous day, and on going to bed became breathless and dizzy; nevertheless she was able to get up and go out shopping next morning; on her way home, she called on a doctor who sent her to hospital, where she remained for ten days. At that time she was described as well nourished, very highly coloured, and with slight cyanosis. The heart was enlarged. There was a loud blowing systolic murmur all over the præcordium and conducted to the axilla; the sounds were well heard in addition to the murmur, and the first sound was reduplicated at the apex. The pulse rate was usually 46 , never less than 44 , and only once as high as 50 during her stay in hospital. A cardiogram showed complete auriculo-ventricular block with an auricular rate of 60 and ventricular rate of 45.6 ; in lead I, the $P$ waves were upright, but QRS and T were completely inverted; in leads II and III the complexes were normal. There was no polycythæmia, the red cell count being 4,760,000 and hæmoglobin 95 per cent. There is no record of the X-ray findings and the films are no longer available.

In 1936 she took work as a housekeeper, a job which she still retains. It was at this time, at the age of 40 , that she began to feel more breathless and found she was becoming more blue. She noticed that her hands were blue, whereas hitherto the high colour was confined to the face. She could walk smartly for short distances without dyspnœa, but could not go far. At her work, she had to sit down and rest from time to time, but she had not had to go on the sick list. Within the last few months she has had a harsh cough from time to time, and has been hoarse for a day or two at a time; some two or three months ago she had a blood-stained spit, and recently the spit has on occasion been slightly streaked with blood. She has never fainted, and she has never had anything resembling a StokesAdams attack.

Examination. She is a small, underdeveloped, thin woman with a slight scoliosis. There is intense injection of the malar regions with small venules visible, the colour being a reddish violet ; in addition to this, there is cyanosis of the lips and hands. The heart is considerably enlarged, the apex being in the mid-axillary line, six and a half inches from the mid-line. The first sound at the apex is loud and accompanied by a soft blowing murmur; the second sound is reduplicated. The murmur can be followed medially for a short distance, but not further than the mid-clavicular line; there are no murmurs elsewhere. The pulse was 48 and regular, save for an occasional extrasystole. Blood pressure was 124/80 in February and 114/74 in September, 1942. The lungs showed generalized bronchitis in February, but were clear in September. There was albuminuria, but neither enlargement of the liver nor œdema.

The electrocardiogram (Fig. 1), substantially unchanged since 1934, shows complete auriculoventricular block with an auricular rate of 68 and a ventricular rate of 46 . The auricular complexes are upright in all leads; the ventricular complexes (QRS and T) are inverted in lead I, resembling those seen in dextrocardia. 


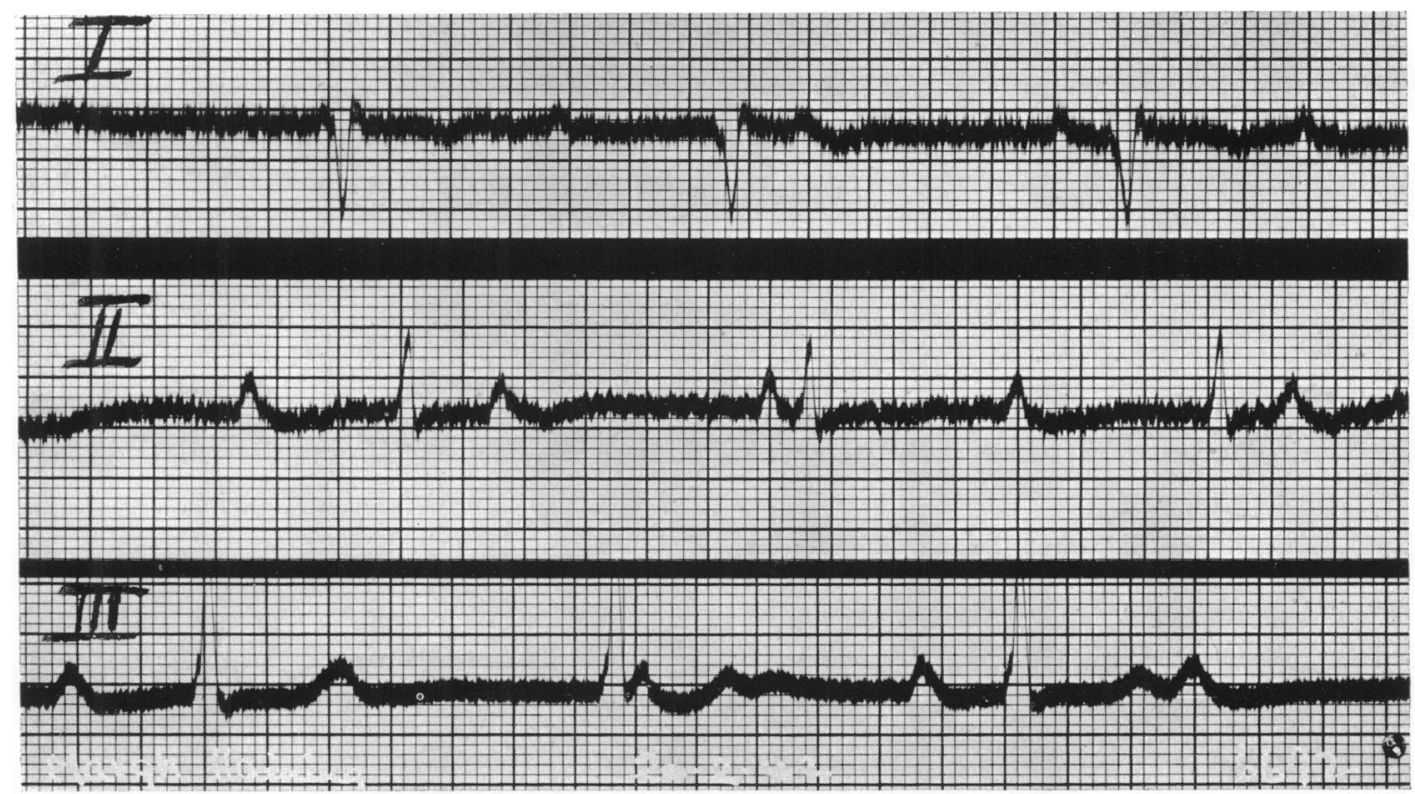

FIG. 1.-Electrocardiogram showing complete heart block and changes somewhat similar to those found with dextrocardia.

Skiagrams of the heart in the antero-posterior and oblique positions are shown in Fig. 2-4. The report on screening (Dr. J. G. McWhirter) is as follows :- "The transverse diameter of the cardiac shadow is increased beyond normal limits and the appearances suggest that this is due to right ventricular hypertrophy. The main branches of the pulmonary artery are enormously dilated and pulsation is easily seen in them. The main pulmonary artery is large and is easily seen in the right oblique position causing some indentation of the œsophagus. The lower end of the esophagus is also displaced backwards and to the right by an enlarged left auricle. The aortic knob is not visible in the anterior view and in the left oblique position the aortic window is obscured by the large pulmonary vessels. The appearances are those of atrial septal defect. There is scoliosis of the dorsal spine."

The patient is active in her movements and walks very smartly without dyspnœa or visible increase in cyanosis; but she says that if she tries to walk any distance she becomes breathless. When she reported back in September, 1942, she had a harsh brassy cough and hoarseness, which suggested the possibility of a recurrent laryngeal nerve paralysis; but laryngoscopic examination (Dr. T. O. Howie) showed a simple laryngitis with congestion of the cords, and no evidence of paralysis.

\section{Discussion}

There can be little doubt, in the first place, that this patient's heart block is congenital, and in the second place that she has an atrial septal defect. The ventricular rate of 46 points to a congenital as opposed to an acquired block; the ventricular complexes resembling those found in dextrocardia are equally suggestive of a congenital lesion. The increasing cyanosis in later life and the gross distension of the pulmonary artery and its main branches without congestion of the periphery of the lung fields are features described by Bedford, Papp, and Parkinson (1941), as characteristics of atrial septal defect.

There is one respect in which the skiagrams of the present case differ from those published by Bedford, Papp, and Parkinson in their series, and from those of two cases of atrial septal defect seen by the author. Prominence of the conus in the antero-posterior view is a usual feature in cases of A.S.D., but is absent in the present case. The contour of this patient's heart in the antero-posterior view resembles that of a case of ventricular septal defect with congenital block published by Stein and Uhr (1942); their case, however, lacks the distension of the pulmonary artery branches. Gross enlargement of the pulmonary artery is stated by Bedford, Papp, and Parkinson to be most exceptional in isolated ventricular septal defect; and they report that bulging of the pulmonary arc was absent in one of their cases of A.S.D., which showed a rounded left border, while another showed a straight left border comparable with that of mitral stenosis. 

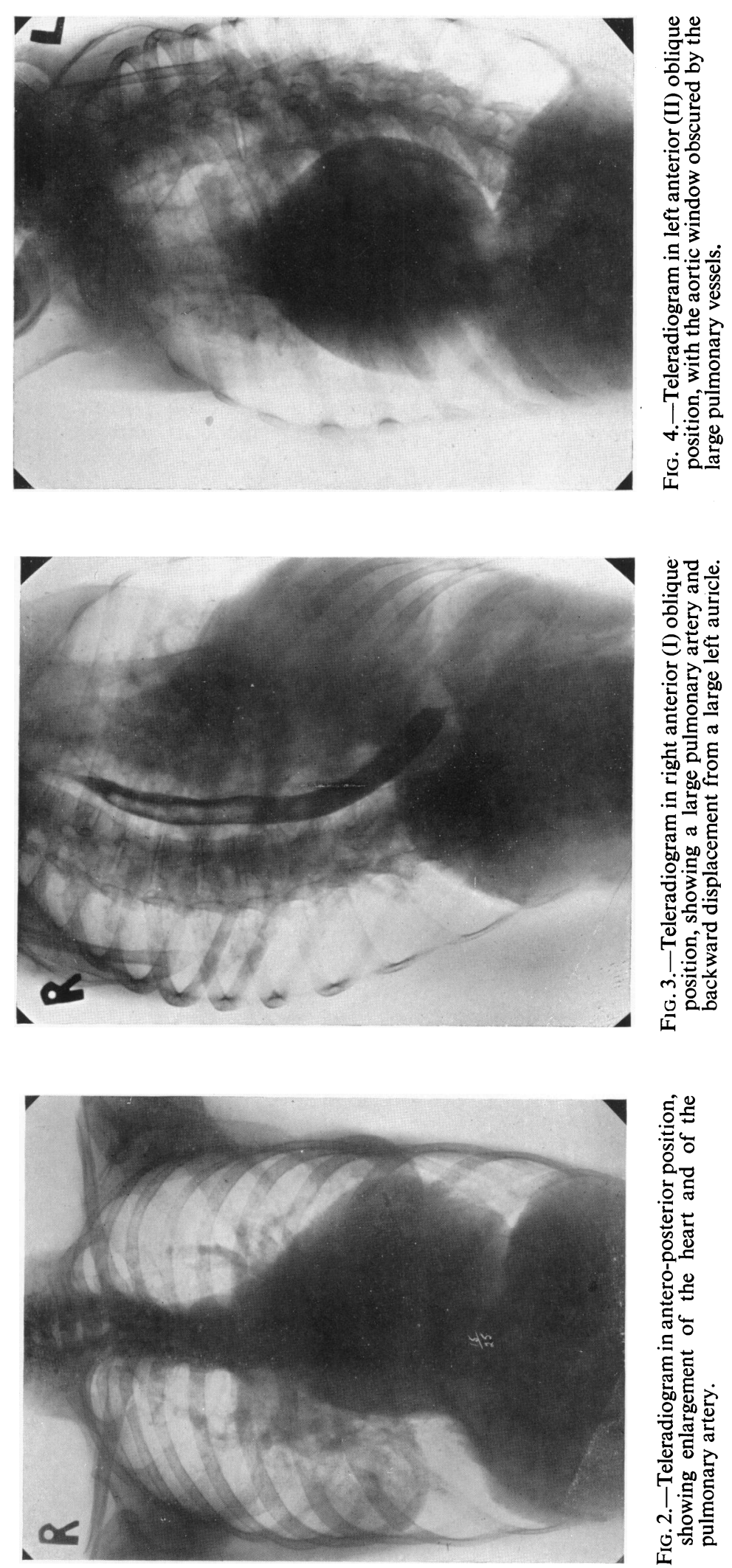
The cause of the block in this case is thought to be a concomitant ventricular septal defect. The combination of atrial septal defect with ventricular septal defect is not uncommon; and although complete block is rare with atrial septal defect (it was present in none of Bedford, Papp, and Parkinson's cases) it has been described (Taussig et al., 1938). The diagnosis of ventricular septal defect was, in fact, suggested at the time of her admission to hospital in 1934 on the grounds of the character of the murmur and the electrocardiographic findings.

The absence of the characteristic "bruit de Roger" at the present time could be explained in two ways. First, a fall in pressure in the left ventricle with a rise in right ventricular pressure may have equalized the pressure on the two sides with consequent disappearance of the murmur. Alternatively, its disappearance may have been brought about by rotation. Bedford, Papp, and Parkinson have shown that in A.S.D. there is progressive enlargement of the right ventricle which comes to form the apex and displaces the left ventricle backwards; rotation of the ventricles in this direction might well displace the murmur of a ventricular septal defect towards the left, that is to say towards the apex, where a systolic murmur is still audible in the present case.

The electrocardiographic features are curious; while the auricular complexes are upright in all leads, all deflections of the ventricular complexes are inverted in lead I. The ventricular complexes (but not the auricular complexes) are identical with those found in dextrocardia. The only other condition in which inversion of TI may be associated with an apparent Tight axial deviation is the QTI type of coronary thrombosis, a possibility that does not arise in this case. Apart from the conditions mentioned, I have never seen $\mathrm{TI}$ inversion resulting from simple right axial deviation without inversion of TII and TIII. Bedford, Papp, and Parkinson, however, record it in two of their cases of A.S.D. It is suggested that this feature of the cardiogram may also be due to rotation; with sufficient enlargement of the right ventricle towards the left and consequent displacement of the left ventricle backwards and towards the right, the interventricular septum will also be rotated clockwise; a ventricular electrocardiogram resembling that of dextr scardia might well be produced in this manner.

\section{SUMMARY}

A case of atrial septal defect with ventricular septal defect and congenital complete heart block is described and discussed. She had fairly good health until she was 40 , and was still working as a housekeeper at 46 years of age.

\section{REFERENCES}

Bedford, D. E., Papp, C., and Parkinson, J. (1941). Brit. Heart J., 3, 37.

Stein, W., and Uhr, J. S. (1942). Ibid. 4, 7.

Taussig, H. B., Harvey, A. McG., and Follis, R. H. (1938). Bull. Johns Hopkins Hosp., 63, 61. 